\title{
Fostering Open Science at WSL with the EnviDat Environmental Data Portal
}

EnviDat is the institutional research data portal of the Swiss Federal Institute for Forest, Snow and Landscape WSL. The portal is designed to provide solutions for efficient, unified and managed access to the WSL's comprehensive reservoir of monitoring and research data, in accordance with the WSL data policy. Through EnviDat, WSL is fostering open science, making curated, quality-controlled, publication-ready research data accessible. Data producers can document author contributions for a particular data set through the EnviDat-DataCRediT taxonomy. The publication of research data sets can be complemented with additional digital resources, such as, e.g., supplementary documentation, processing software or detailed descriptions of code (i.e. as Jupyter Notebooks). The EnviDat Team is working towards generic solutions for enhancing open science, in line with WSL's commitment to accessible research data. 


\section{Fostering Open Science at WSL with the EnviDat} 2 Environmental Data Portal

3

Ionuț Iosifescu Enescu', Marielle Fraefel', Gian-Kasper Plattner' ${ }^{1}$, Lucia Espona-Pernas', Dominik Haas-Artho' ${ }^{1}$, Michael Lehning ${ }^{23}$, Konrad Steffen ${ }^{134}$

Swiss Federal Institute for Forest, Snow and Landscape WSL, Birmensdorf, Switzerland ${ }^{2}$ WSL Institute for Snow and Avalanche Research SLF, Davos, Switzerland ${ }^{3}$ École Polytechnique Fédérale de Lausanne EPFL, Lausanne, Switzerland ${ }^{4}$ ETH Zurich, Zurich, Switzerland

Corresponding Author: Ionuț Iosifescu Enescu

'Eidg. Forschungsanstalt WSL, Zürcherstrasse 111, CH-8903 Birmensdorf, Switzerland Email address: ionut.iosifescu@wsl.ch

\section{ABSTRACT}

EnviDat is the institutional research data portal of the Swiss Federal Institute for Forest, Snow and Landscape WSL. The portal is designed to provide solutions for efficient, unified and managed access to the WSL's comprehensive reservoir of monitoring and research data, in accordance with the WSL data policy. Through EnviDat, WSL is fostering open science, making curated, quality-controlled, publication-ready research data accessible. Data producers can document author contributions for a particular data set through the EnviDat-DataCRediT taxonomy. The publication of research data sets can be complemented with additional digital resources, such as, e.g., supplementary documentation, processing software or detailed descriptions of code (i.e. as Jupyter Notebooks). The EnviDat Team is working towards generic solutions for enhancing open science, in line with WSL's commitment to accessible research data.

\section{KEYWORDS}

Open Science, EnviDat, Environmental Science, Data Sharing, Research Data Management 


\section{INTRODUCTION}

The Swiss Federal Institute for Forest, Snow and Landscape WSL, a research institute of the Swiss national network of federal institutes of technology and research institutions (ETH Domain), is developing the institutional environmental data portal EnviDat (Figure 1). EnviDat is designed to provide unified and managed access to WSL's environmental monitoring and research data. WSL has a long tradition in data collection. WSL research datasets cover research themes ranging from forest ecosystems, snow and ice, landscape, biodiversity to natural hazards and include long-term monitoring datasets spanning over a century. Such datasets are particularly valuable for studying the terrestrial environment and for obtaining an integrated view of the Earth System.

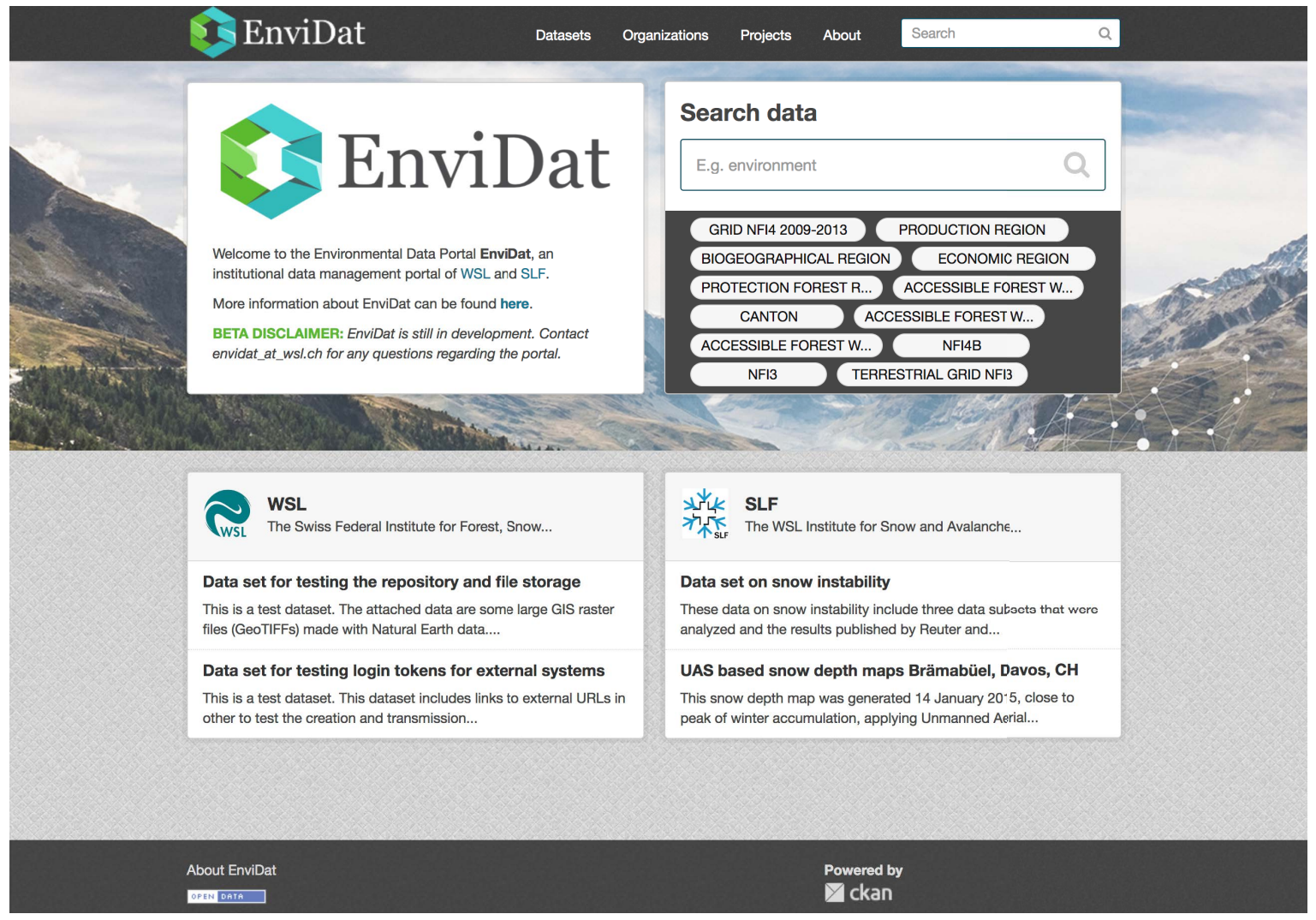

Figure 1: The EnviDat Homepage (September 2018)

The EnviDat environmental data portal has been selected by the WSL board of directors as one of three strategic initiatives of WSL for the planning period 2017-2020, highlighting the importance of research data management at the institutional level. WSL recently also put in place an overarching data policy with the goal to make research data accessible within two years after the completion of a research project (or a program phase for long-term research programs and monitoring projects). Consequently, the EnviDat strategic initiative is revolving around developing solutions for efficient, unified and managed access to the WSL's comprehensive reservoir of monitoring and research data, in accordance with the WSL data policy. 
61

62

63

64

65

66

67

68

69

70

71

72

73

74

75

76

77

78

79

80

\section{OPEN SCIENCE THROUGH ENVIDAT}

WSL is fostering open science through EnviDat (a) by making research data accessible and (b) by offering WSL data producers to publish the datasets with a DOI.

EnviDat services in the area of research data management focus on nine major activity areas.

Seven out of nine are currently active, namely (1) development of a concept for EnviDat, and by extension, a concept for the research data management at WSL, (2) data publication with provision of metadata and Document Object Identifiers (DOIs), (3) maintenance of an efficient repository for publication data, (4) integration of existing operational systems into EnviDat, such as the Swiss Long-term Forests Ecosystem Research Program (LWF) and the Swiss National Forest Inventory (NFI), (5) guidance to researchers regarding options for publishing curated data, (6) provision of versioning capabilities for datasets, and (7) contacts and exchange with the international RDM community. Furthermore, it is planned to add (8) solutions for integrated management, validation visualization and publication of streaming sensor data (such as meteorological measurements) and (9) solutions for visualization and management of GIS data.

WSL's goal to foster open science is supported by several of these services. In EnviDat, WSL scientists can register metadata about the data and provide access to the actual data. For the latter, they can upload the data to the EnviDat data repository or link it from an operational information management system or database. In September 2018, EnviDat achieved the publication of more than one hundred environmental datasets for Switzerland and beyond (Figure 2).

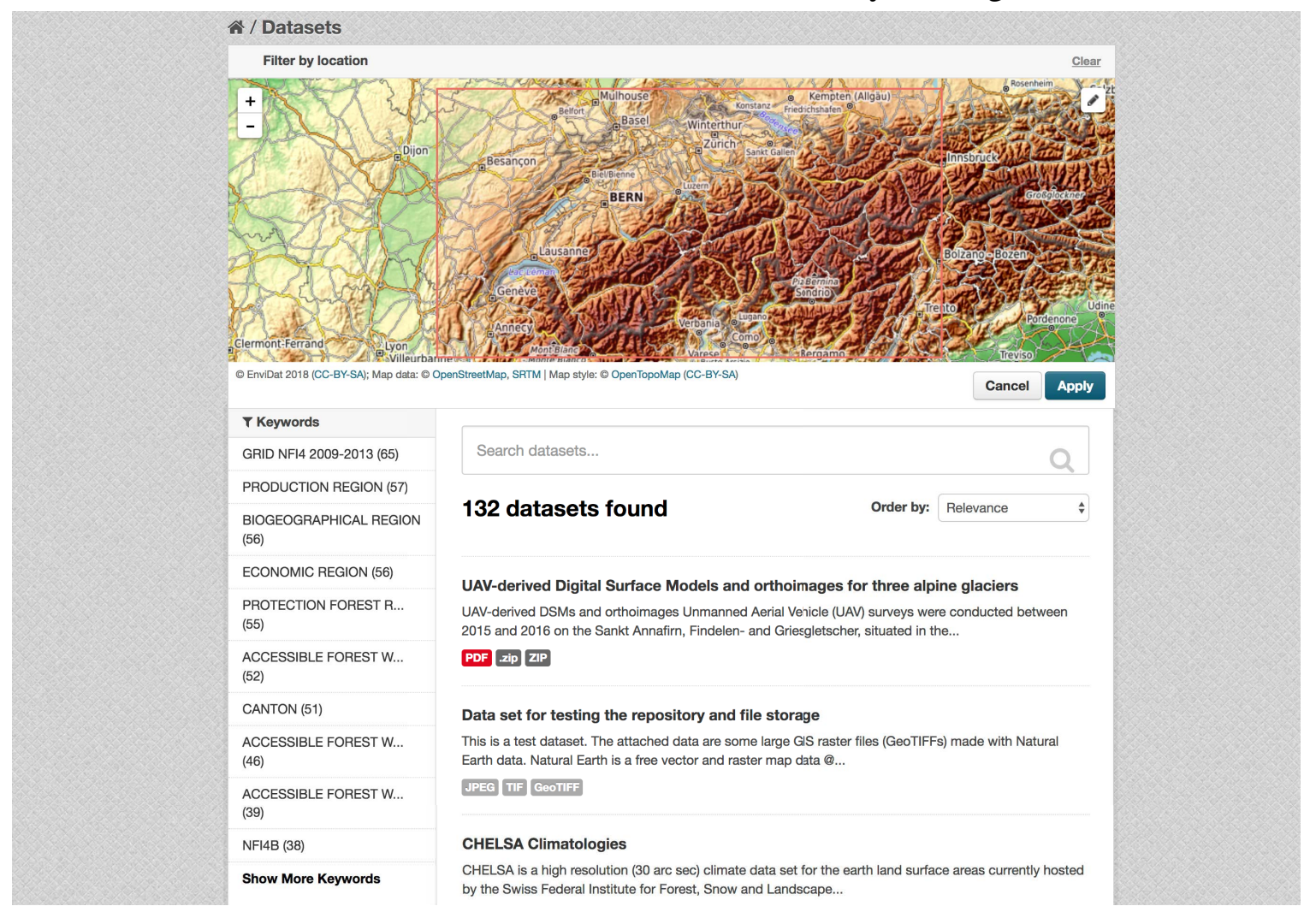

Figure 2: The EnviDat Datasets Page (September 2018) 
WSL takes an approach of distributed data management where the responsibility to curate research data remains with the experts and original data providers. EnviDat requires that data providers register curated, quality-controlled, publication-ready data sets, that are ideally conforming to the FAIR (Findability, Accessibility, Interoperability and Reusability) principles. Inspired by the CASRAI Contributor Roles Taxonomy, we have defined the EnviDat-DataCRediT taxonomy' for data authorship, explicitly allowing the documentation of individual author contributions involved in the publication of a particular data set in EnviDat.

As mentioned above, EnviDat is designed to provide unified and managed access to research data. However, publishing data with appropriate metadata is not always enough to effectively foster open science. There is still the problem of sharing and reproducing the computations needed to process and visualize the data, comparable e.g. to the methodologies presented in research papers. EnviDat already allows and recommends to WSL scientists to complement data publication with additional useful resources in digital form, such as supplementary documentations or processing software. In this context, Jupyter Notebooks emerged as a solution for documenting code in a wide range of programming languages ${ }^{2}$ often used by environmental researchers, such as Python, R, Octave, Scilab, Matlab, C, Java or Scala.

\section{SHOWCASE AND RESULTS}

To showcase the integration and usefulness of Jupyter Notebooks in a data portal, we present a geospatial analysis example for road density calculation. In ecology, the presence of roads is often used as an indicator for the degree of human disturbance in a region. The effect of roads on movement patterns and habitat selection for different species and on different scales has been analysed in numerous studies (Fahrig \& Rytwinski, 2009). While roads may act as barriers to the movement of certain animal species (habitat fragmentation) and directly increase mortality by traffic, they can also facilitate movement or provide food for other species. In our example, we examine road densities in the neighbourhood of sample locations using Python. The data used (point sample locations and road geometries) can be retrieved from EnviDat, while the Python script is made available as a Jupyter notebook on EnviDat (Figure 3).

Jupyter notebooks are an open document format based on JSON that mix the code with descriptive narrative text, as well as rich output. Consequently, similar to the above Python Notebook example, WSL scientists and EnviDat data providers are now encouraged to share detailed descriptions of their code with the community. In the coming years, EnviDat aims for a deeper integration of user-uploaded Jupyter Notebooks. Small scale, proof-of-concept work has been

\footnotetext{
${ }^{1} \mathrm{https}: / /$ www.wsl.ch/datacredit/

${ }^{2}$ https://github.com/jupyter/jupyter/wiki/Jupyter-kernels
} 
started for opening Jupyter notebooks hosted in EnviDat in an executable environment based on BinderHub $^{3}$. Yet, the development of a generic solution that would offer WSL researchers the opportunity to access their code from anywhere on the existing EnviDat infrastructure is still underway.
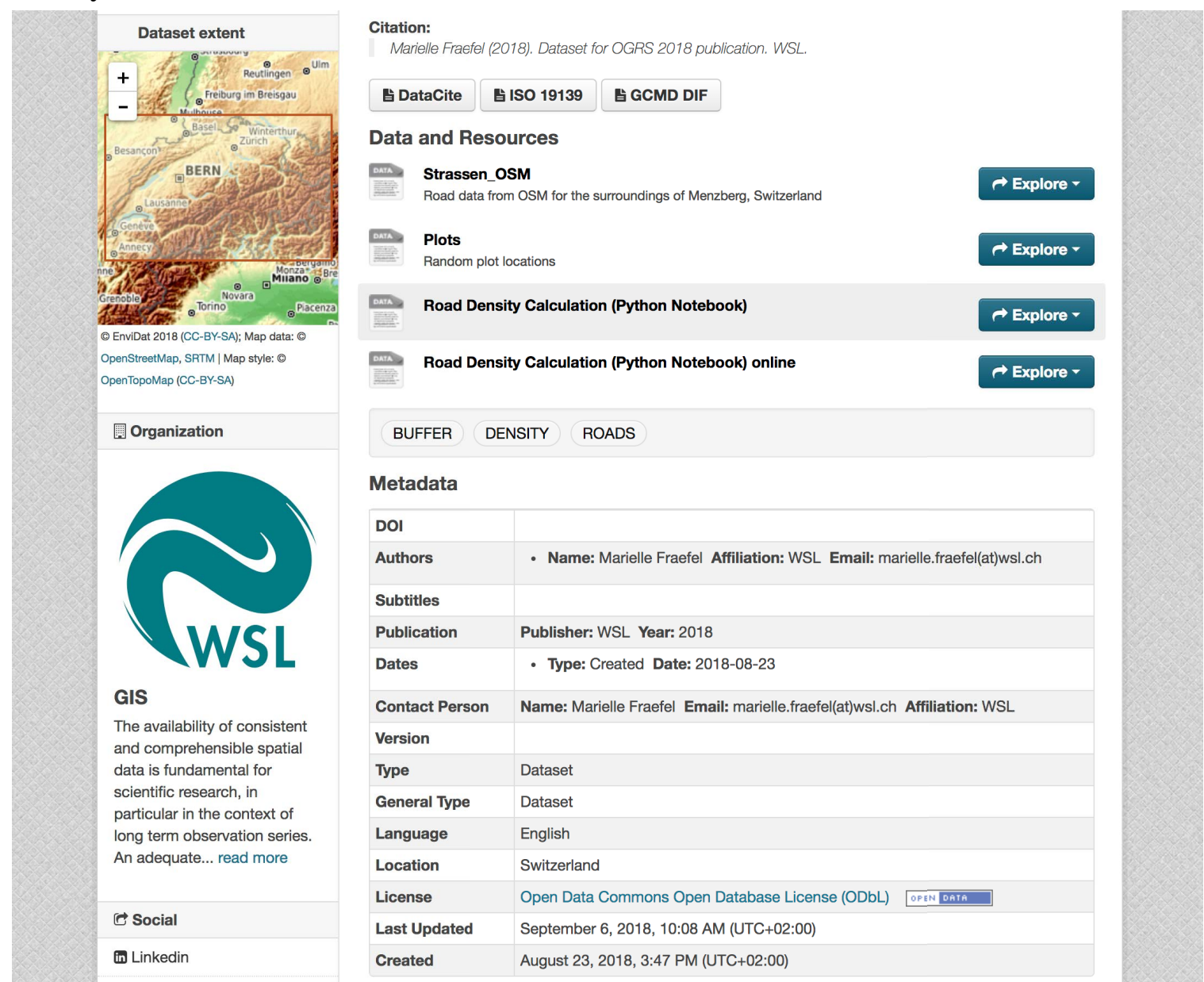

Figure 3: Example of Jupyter notebooks in EnviDat

\section{DISCUSSION AND CONCLUSIONS}

Beyond the challenges related to the technical implementation, additional important challenges are the proper integration of proprietary software libraries (e.g. ArcGIS) and the limited IT infrastructure resources available for running Jupyter Notebooks as a service. In conclusion, EnviDat is working on a generic forward-looking solution, that is equally applicable to the geospatial domain, for enhancing Open Science support, following WSL's commitment to accessible research data in order to advance science.

\footnotetext{
${ }^{3}$ https://github.com/jupyterhub/binderhub
} 
135

136

137

138

139

140

141

142

143

144

145

146

\section{ACKNOWLEDGEMENTS}

The authors would like to acknowledge the support of the IT department, as well as the inputs to the EnviDat program given by the members of the EnviDat User Group and of the GIS Group at Swiss Federal Institute for Forest, Snow and Landscape WSL. We will also like to thank Oleg Lavrovsky, that brought the use of Jupyter notebooks in the attention of the EnviDat team by creating a Jupyter notebook for visualizing an EnviDat dataset documenting fatal avalanche accidents in Switzerland.

\section{REFERENCES}

Fahrig, L. \& Rytwinski, T. 2009. Effects of Roads on Animal Abundance: an Empirical Review and Synthesis. Ecology and Society, 14. 